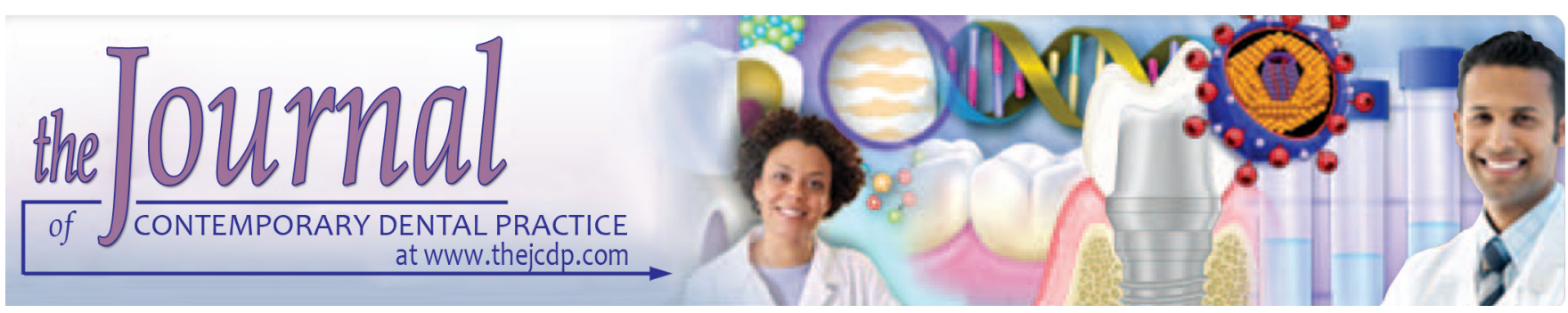

\title{
Correlation of Orthodontic Treatment by Fixed or Myofunctional Appliances and Periodontitis: A Retrospective Study
}

\author{
${ }^{1}$ Kanchan Sharma, ${ }^{2}$ Sukhpreet Mangat, ${ }^{3}$ Modi S Kichorchandra, ${ }^{4}$ Akash Handa, ${ }^{5}$ Suresh Bindhumadhav \\ ${ }^{6}$ Meenakshi Meena
}

\begin{abstract}
Introduction: Malocclusion plays an important role in the development of periodontitis. Thus, by treating malocclusion, a good gingival health can be achieved. This study was conducted to establish the correlation between orthodontic tooth movement and periodontitis.

Materials and methods: This is a retrospective study conducted on 220 patients who underwent orthodontic treatment for malocclusion. They were divided into two groups: Group I patients were treated with fixed orthodontics, while group II patients received myofunctional appliances.
\end{abstract}

Results: The value for plaque, gingival recession, and tooth mobility significantly increased in group I patients. However, the difference was statistically nonsignificant in group II patients.

Conclusion: The authors concluded that there is correlation between malocclusion and periodontitis. Malocclusion leads to periodontitis.

Clinical significance: Malocclusion is the main reason for the development of poor periodontal health. Combined effort has to be played by both periodontist and orthodontist for the treatment of various orthodontic-periodontal problems.

Keywords: Malocclusion, Myofunctional appliances, Periodontitis.

${ }^{1}$ Department of Oral Pathology and Microbiology, Maharaja Ganga Singh Dental College \& Research Centre, Sri Ganganagar Rajasthan, India

${ }^{2}$ Dentzz Dental Care Centre, Mumbai, Maharashtra, India

${ }^{3}$ Department of Orthodontics, Kejal Sarvajanik Hospital, Navsari Gujarat, India

${ }^{4}$ Private Practitioner, Hazaribag, Jharkhand, India

${ }^{5}$ Private Practitioner, Bengaluru, Karnataka, India

${ }^{6}$ Department of Periodontology, Mahatma Gandhi Dental College \& Hospital, Jaipur, Rajasthan, India

Corresponding Author: Kanchan Sharma, Department of Oral Pathology and Microbiology, Maharaja Ganga Singh Dental College \& Research Centre, Sri Ganganagar, Rajasthan, India Phone: +919501544877, e-mail: drkanchansharma@gmail.com
How to cite this article: Sharma K, Mangat S, Kichorchandra MS, Handa A, Bindhumadhav S, Meena M. Correlation of Orthodontic Treatment by Fixed or Myofunctional Appliances and Periodontitis: A Retrospective Study. J Contemp Dent Pract 2017;18(4):322-325.

Source of support: Nil

Conflict of interest: None

\section{INTRODUCTION}

Malocclusion leads to poor periodontal health. Orthodontic treatment aims at providing an acceptable functional and esthetic occlusion and improvement in the masticatory function. ${ }^{1}$ By treating malocclusion and reducing occlusion trauma, a better periodontal health is achieved. Hence, it has been suggested that orthodontic treatment leads to an improved periodontal status. ${ }^{2}$ Irregular teeth are difficult to clean as compared with straight teeth. Orthodontic treatment poses difficulty in complete oral hygiene procedures and as a result promoting conversion of subgingival plaque to a more aggressive periopathogenic flora. There is accumulation of plaque around the orthodontic appliances, such as brackets and wires resulting in gingivitis and periodontitis. ${ }^{3}$

Ngom et $\mathrm{al}^{4}$ in their study found strong correlations between malocclusions and periodontal condition and concluded that malocclusion is a risk factor for periodontal disease. It has been suggested that orthodontic appliances contribute to chronic infection, inflammatory hyperplasia, irreversible loss of attachment, and gingival recession. Few studies have shown that labial movement of the mandibular incisors during orthodontic treatment leads to gingival recession, while others have found no, such association between orthodontic tooth movement and gingival recession. ${ }^{5,6}$ 
Thus, this study was conducted to establish the correlation between orthodontic tooth movement and periodontitis.

\section{MATERIALS AND METHODS}

This retrospective study was conducted on 220 patients between 2010 and 2015 who had completed orthodontic treatment in Department of Orthodontics. Only those patients, whose pre and posttreatment records and patients with pre and posttreatment clinical intraoral photographs were available, were included in the study. Patients with cleft lip and palate were excluded from the study.

Following points were recorded using patient photographs:

- Presence or absence of plaque preoperatively and postoperatively

- Presence or absence of labial gingival recession before and after orthodontic treatment

- Comparison of tooth mobility pre- and postoperatively. Both photographs and panoramic radiographs were analyzed by experienced operator. Results thus obtained were subjected to statistical analysis using Statistical Package for the Social Sciences version 20; $p<0.05$ was considered statistically significant.

\section{RESULTS}

Table 1 shows the distribution of patients. Total patients were 220, which included 90 males and 130 females. Table 2 shows that patients received either fixed orthodontics or myofunctional appliances for various types of malocclusion. Out of 220 patients, 140 patients received fixed orthodontics (group I) (males - 60, females - 80) and 80 patients (males -30 , females -50 ) received myofunctional appliances (group II).

About 32 males and 40 females were of class I malocclusion, and they were treated with fixed orthodontic

Table 1: Distribution of patients

\begin{tabular}{lll}
\hline & Total $=220$ \\
\hline Male & Female \\
\hline 90 & 130 \\
\hline
\end{tabular}

appliances (group I). About 15 males and 28 females were of class II malocclusion, and they underwent treatment with fixed orthodontic appliances (group I). About 13 males and 12 females had class III malocclusion, and they also received fixed appliances (group I).

A total of 36 patients (males -12 , females -24 ) were suffering from class I malocclusion and they got myofunctional appliances (group II). About 27 patients (males - 11, females -16) were of class II malocclusion, and they also received myofunctional appliances (group II); 17 patients (males - 7, females - 10) suffered from class III malocclusion, and they underwent treatment with myofunctional appliances (group II).

Table 3 shows the distribution of plaque, gingival recession, and tooth mobility values in fixed and myofunctional orthodontics. Patients who underwent fixed orthodontics (group I), the plaque value $(3.2 \pm 6.5$ to $5.6 \pm 9.7)$ was significantly increased $(p=0.02)$. However, there was nonsignificant increase $(\mathrm{p}=0.4)$ in plaque value $(2.5 \pm 6.2$ to $3.2 \pm 6.6)$ in patients who received myofunctional appliances (group II). The gingival recession values $(0.18 \pm 1.23$ to $0.58 \pm 1.49)$ also showed significant increase $(\mathrm{p}=0.00)$ in patients treated with fixed orthodontics. In group II, gingival recession value $(0.12 \pm 1.11$ to $0.19 \pm 1.32$ ) showed nonsignificant increase. The tooth mobility values increased $(0.16 \pm 1.88$ to $0.54 \pm 1.90)$ in group I patients and those who were treated with myofunctional appliances; their values also increased $(0.13 \pm 1.42$ to $0.16 \pm 1.54)$. However, the difference was statistically nonsignificant in group II.

Table 2: Distribution of patients according to orthodontic treatment

\begin{tabular}{lll}
\hline \multicolumn{1}{c}{ Total = 220 } & & \\
\hline Orthodontic treatment & Male & Female \\
\hline Fixed orthodontics (group I) & & \\
Class I & 32 & 40 \\
Class II & 15 & 28 \\
Class III & 13 & 12 \\
Myofunctional orthodontics (group II) & & \\
Class I & 12 & 24 \\
Class II & 11 & 16 \\
Class III & 7 & 10 \\
\hline
\end{tabular}

Table 3: Distribution of plaque, gingival recession, and tooth mobility values in fixed and myofunctional orthodontics

\begin{tabular}{llllllll}
\hline & \multicolumn{3}{c}{ Fixed orthodontics (group I) } & & \multicolumn{2}{c}{ Myofunctional orthodontics (group II) } \\
\cline { 2 - 3 } Parameter & Before treatment & After treatment & $p$-value & & Before treatment & After treatment & $p$-value \\
\hline Plaque (mean \pm SD) & $3.2 \pm 6.5$ & $5.6 \pm 9.7$ & $0.02 \mathrm{~S}$ & & $2.5 \pm 6.2$ & $3.2 \pm 6.6$ & $0.4 \mathrm{NS}$ \\
Gingival recession (mean \pm SD) & $0.18 \pm 1.23$ & $0.58 \pm 1.49$ & $0.00 \mathrm{~S}$ & $0.12 \pm 1.11$ & $0.19 \pm 1.32$ & $0.2 \mathrm{NS}$ \\
Tooth mobility (mean \pm SD) & $0.16 \pm 1.88$ & $0.54 \pm 1.90$ & $0.00 \mathrm{~S}$ & $0.13 \pm 1.42$ & $0.16 \pm 1.54$ & $0.3 \mathrm{NS}$ \\
\hline
\end{tabular}

SD: Standard deviation; S: Significant; NS: Nonsignificant 


\section{DISCUSSION}

Patients undergoing orthodontic treatment due to brackets and wires were provided favorable environment for plaque accumulation. Hence, it is very important to maintain oral hygiene in patients undergoing orthodontic treatment. ${ }^{7}$

In this study, we included 220 patients (males - 90, females - 130) who underwent orthodontic treatment (Table 1). In this study, we evaluated the presence of plaque, gingival recession, and grading of tooth mobility through the patient's records like preoperative photographs and panoramic radiographs which were compared with postoperative records. All types of malocclusion, such as class I, II, and III were included in the study. Patients received either fixed orthodontics or myofunctional appliances. Out of 220 patients, 140 patients received fixed orthodontics (males -60 , females -80 ) and 80 patients (males - 30, females - 50) were treated with myofunctional appliances. In group I, 72 patients (males - 32, females - 40) were of class I malocclusion; 43 patients (males - 15, females -28) were of class II malocclusion; and 25 patients (males - 13, females - 12) were of class III malocclusion.

In group II, 80 patients (males -30 , females -50 ) obtained myofunctional orthodontics, out of which 36 patients (males - 12, females - 24) were of class I malocclusion; 27 patients (males - 11, females -16) were of class II malocclusion; and 17 patients (males - 7, females - 10) were of class III malocclusion (Table 2).

We evaluated plaque index (PI), gingival recession, and tooth mobility values in patients receiving fixed and myofunctional orthodontics. In group I, before undergoing treatment, the value for plaque $(3.2 \pm 6.5)$ showed a significant increase $(5.6 \pm 9.7)$ after treatment. The values for the gingival recession and tooth mobility were $0.18 \pm 1.23$ and $0.16 \pm 1.88$ respectively, before treatment which became $0.58 \pm 1.49$ and $0.54 \pm 1.90$ after treatment. All these parameters showed a significant increase (Table 3 ). The results of our study were in accordance to Liu et $\mathrm{al}^{8}{ }^{8}$ who in his study concluded that fixed orthodontic treatment results in significant increase in PI and gingival index after orthodontic treatment.

In group II, the values for plaque, gingival recession, and tooth mobility were $2.5 \pm 6.2,0.12 \pm 1.11$, and $0.13 \pm 1.42$ respectively. Postoperatively, these values increased to $3.2 \pm 6.6,0.19 \pm 1.32$ and $0.16 \pm 1.54$ respectively (Table 3). No statistically significant difference was found in group II patients before and after treatment.

Type of orthodontic treatment plays an important role in developing periodontitis. Removable appliances place intermittent tipping forces on teeth, but fixed appliances can create continuous multi directional forces. Thus, heavy forces cause bone resorption at the side of pressure. ${ }^{9}$
The gingival recession was mostly seen in upper and lower anterior teeth, because most of the orthodontic tooth movement was achieved in these two regions. Gingival recession was evaluated using Miller classification. ${ }^{10}$ Dorfman, ${ }^{5}$ in his study, suggested that gingival recession is mostly seen in more proclined teeth as compared with less proclined teeth. Thus for orthodontic treatment in patients with periodontitis, the clinical attachment level, tooth mobility, and the inclination of incisors should be considered.

Bollen ${ }^{11}$ in 2008 in his study found a correlation between the presence of a malocclusion and periodontal disease. He concluded that patients with greater malocclusion have more severe periodontal disease. Hence, it can be stated that the variation in the design and the material used for orthodontic appliances also play an important role in the development of periodontitis. Thus, a combined effort has to be played by both periodontist and the orthodontist for the treatment of various orthodontic-periodontal problems. ${ }^{12}$

A high standard of oral hygiene is required for patients undergoing orthodontic treatment. As plaque accumulates around orthodontic appliances, such as brackets and wires, patients should be advised to maintain oral hygiene, and the effectiveness of the oral hygiene regime should be monitored.

\section{CONCLUSION}

The authors concluded that there is correlation between malocclusion and periodontitis. Hence, maintenance of oral hygiene is very essential in patients with malocclusion and this has to be maintained before undergoing orthodontic treatment. Also, it has been suggested that treating malocclusion with fixed orthodontics has detrimental effects on periodontium.

\section{REFERENCES}

1. Shivakumar K, Chandu G, Shafiulla M. Severity of malocclusion and orthodontic treatment needs among 12- to 15-year-old school children of Davangere District, Karnataka, India. Eur J Dent 2010 Jul;4(3):298-307.

2. Zachrisson BU, Zachrisson S. Gingival condition associated with partial orthodontic treatment. Acta Odontol Scand 1972 Mar;30(1):127-136

3. Thornberg MJ, Riolo CS, Bayirli B, Riolo ML, Van Tubergen EA, Kulbersh R. Periodontal pathogen levels in adolescents before, during, and after fixed orthodontic appliance therapy. Am J Orthod Dentofacial Orthop 2009 Jan;135(1):95-98.

4. Ngom PI, Benoist HM, Thiam F, Diagne F, Diallo PD. Influence of orthodontic anomalies on periodontal condition. Odontostomatol Trop 2007 Jun;30(118):9-16.

5. Dorfman HS. Mucogingival changes resulting from mandibular incisor tooth movement. Am J Orthod 1978 Sep;74(3):286-297. 
6. Hollender L, Rönnerman A, Thilander B. Root resorption, marginal bone support and clinical crown length in orthodontically treated patients. Eur J Orthod 1980;2(4): 197-205.

7. Van Gastel J, Quirynen M, Teughels W, Carels C. The relationships between malocclusion, fixed orthodontic appliances and periodontal disease. A review of the literature. Aust Orthod J 2007 Nov;23(2):121-129.

8. Liu H, Sun J, Dong Y, Lu H, Zhou H, Hansen BF, Song X. Periodontal health and relative quantity of subgingival Porphyromonas gingivalis during orthodontic treatment. Angle Orthod 2011 Jul;81(4):609-615.
9. Sanders NL. Evidence-based care in orthodontics and periodontics: a review of the literature. J Am Dent Assoc 1999 Apr;130(4):521-527.

10. Miller PD Jr. A classification of marginal tissue recession. Int J Periodontics Restorative Dent 1985;5(2):8-13.

11. Bollen AM, Cunha-Cruz J, Bakko DW, Huang GJ, Hujoel PP. The effects of orthodontic therapy on periodontal health: a systematic review of controlled evidence. J Am Dent Assoc 2008 Apr;139(4):413-422.

12. Mudasar A, Munaza S, Mohammad Y, Faiqah L. Perioortho interrelationship: a review. Scholars J Appl Med Sci 2016;4:2238-2243. 